\section{Impact of anterior capsule polishing on anterior capsule opacification after cataract surgery: a randomized clinical trial}

SK Shah, MR Praveen, A Kaul, AR Vasavada, GD Shah and BR Nihalani
Iladevi Cataract and IOL Research Centre, Raghudeep Eye Clinic, Memnagar, Ahmedabad, India

Correspondence: AR Vasavada, Raghudeep Eye Clinic, lladevi Cataract \& IOL Research Centre, Gurukul Road, Memnagar, Ahmedabad 380052, India

Tel: + 9179274923 03/ 27490909;

Fax: +9179 27411200

E-mail: icirc@

abhayvasavada.com

Received: 3 July 2008 Accepted in revised form: 29 October 2008 Published online: 12 December 2008

\begin{abstract}
Aims To evaluate the effect of anterior capsule polishing on the development of anterior capsule opacification (ACO) in patients undergoing cataract surgery. Methods This prospective randomized observational double-masked clinical trial comprised 120 eyes of 60 consecutive patients with bilateral age-related cataract who underwent phacoemulsification. The patients were randomly assigned to one of the two groups: One eye received a 360 degree anterior capsule polishing (group 1 (cases)) and the fellow eye was without anterior capsule polishing (group 2 (controls)) The primary observation was to observe the development of ACO between the 2 groups, whereas the secondary observation was to measure uveal inflammation. ACO was evaluated at 1 week, 1 month, and 6 months.

Results At the 1-week follow-up, there was no significant difference in the development of ACO between the two groups. At 1 month, $54(\mathbf{9 0} \%)$ eyes developed ACO in controls and $26(43.3 \%)$ eyes in cases $(P<0.001)$. However, at 6 months, there was no significant difference in the development of ACO between controls and cases $(P=0.500)$. The odds of having cells and flare were significantly more in cases compared with controls at first postoperative day (cells: OR, 39.27; 95\% CI, 13.49-114.26 and flare: OR, 48.0; 95\% CI, 15.57-147.97).

Conclusions ACO was significantly lower at 1 month in cases compared with controls. However, the difference in ACO between the two groups was insignificant at 6 months. A significant difference in anterior segment inflammation was documented in cases on the
\end{abstract}

first postoperative day. There was no detectable benefit of performing scraping on the anterior capsule to avoid opacification after phacoemulsification.

Eye (2009) 23, 1702-1706; doi:10.1038/eye.2008.355; published online 12 December 2008

Keywords: age related cataract phacoemulsification; anterior capsule polishing; anterior capsule opacification

\section{Introduction}

The increasing popularity of phacoemulsification and continuous curvilinear capsulorhexis has made IOL implantation in the capsular bag, the most commonly used method of performing cataract surgery. ${ }^{1}$ Despite recent progress in cataract extraction techniques, lens implantation techniques, and IOL design, capsular opacification still remains a problem. ${ }^{2-4}$ Capsular opacification takes place due to proliferation, migration, and differentiation of residual lens epithelial cells (LECs). ${ }^{5}$ These LECs attempt to undergo normal differentiation or epithelial mesenchymal transition (EMT), and consequently form heterogeneous groups of cells in the anterior capsule opacification (ACO) and posterior capsule opacification (PCO). These myofibroblasts type of cells lead to fibrosis of the remnant capsule. ${ }^{6}$ Contact with the IOL optic causes the LECs of the anterior capsule to undergo fibrosis, resulting in fibrotic type of ACO. ${ }^{3,4,7-10}$

Fibrosis of the anterior capsule leads to contraction of the capsulorhexis opening or capsule retraction leading to buttonholing of the 
lens optic and reduction in the free optic zone. The latter may cause decentration of the IOL optic and fibrotic opacification of the posterior capsule. ${ }^{4,9}$ Therefore, the intraoperative removal of the LECs from the anterior lens capsule is becoming increasingly important in cataract surgery to minimize the chances of occurrence of ACO. Several approaches have been devised, such as scratcher, vacuum cleaning, cryo coagulation, wet field coagulation, ultrasound techniques, and chemical application. ${ }^{11-14}$ We hypothesized that polishing the anterior capsule would reduce fibrosis of the anterior capsule. In this study, we have evaluated the effect of anterior capsule polishing on the development of ACO and uveal inflammation.

\section{Materials and methods}

This prospective randomized observational doublemasked clinical trial comprised 120 eyes of 60 consecutive patients with bilateral age-related cataract who underwent phacoemulsification for both the eyes at Iladevi Cataract and IOL Research Centre from March to July 2006. Informed consent was obtained from all patients. Patients older than 45 years with age-related cataract and pupils dilating more than $7 \mathrm{~mm}$ were included in the study. Exclusion criteria were glaucoma, shallow anterior chamber, uveitis, high myopia (axial length $>27.0 \mathrm{~mm}$ ), pseudoexfoliation, diabetes mellitus, traumatic cataracts, posterior polar cataract, subluxated cataracts, previous ocular surgeries, patients allergic to dilating drops, and steroid intake. Intraoperatively, the exclusion criteria were not achieving the total anterior capsule cover on the IOL optic either in both the eyes or only in one eye, sulcus fixated IOL, and any intraoperative complications like posterior capsule rupture. After bimanual irrigation/aspiration, all enrolled patients were randomly assigned to receive either 360 degree anterior capsule polishing (group 1 (cases)) or group 2 (controls) without anterior capsule polishing in the first eye and the alternative in the second eye within a month. A single experienced surgeon (ARV) performed all the surgeries using a standardized surgical technique and topical anaesthesia. Emulsification was performed with the Infiniti (Alcon Laboratories, Forth Worth, TX, USA) phacoemulsifier using standardized surgical techniques described elsewhere. ${ }^{15-17}$ This was followed by bimanual irrigation/ aspiration to ensure thorough and complete cortex removal. The preset parameters were a vacuum of $7 \mathrm{mmHg}$ and an aspiration flow rate of $5 \mathrm{cc} / \mathrm{min}$ in the polish mode. The undersurface of the anterior capsule was polished in all the quadrants and in all the clock hours. The irrigation/ aspiration probes were swiped to achieve total 360 degree polishing. The time scheduled for performing
Table 1 Distribution of the presence or absence of anterior capsular opacification (ACO) at 1 week, 1 month, and 6 months

\begin{tabular}{lcc}
\hline ACO & Yes & No \\
\hline 1 week & & \\
$\quad$ Controls & 0 & 60 \\
Cases & 0 & 60 \\
1 month & & \\
$\quad$ Controls & $54(90.0 \%)$ & $6(10.0 \%)$ \\
Cases & $26(43.3 \%)$ & $34(56.7 \%)$ \\
& & \\
months & & 0 \\
Controls & $60(100 \%)$ & $1(1.7 \%)$ \\
\hline
\end{tabular}

anterior capsule polishing was standardized to $5 \mathrm{~min}$ in this study. An AcrySof (model: SN60AT, Alcon Laboratories, Forth Worth, TX, USA) IOL was implanted in the capsular bag. Postoperatively, standardized postoperative regime was given. Our primary observation was to grade the ACO, whereas our secondary observation was to document the occurrence of uveal inflammation. ACO was evaluated on slit-lamp examination with oblique illumination at $\times 12$ magnification at 1 week, 1 month, and 6 months. As proposed by Werner et al, ${ }^{10}$ ACO was graded on a scale of $0-4$ in the area in which the rhexis was in contact with the IOL optic. The grading scheme was as follows: grade 0 , no opacification; grade 1 , only the edge of capsulorhexis as opacified; grade 2, diffuse opacification with folds; grade 3, intense opacification with folds; and grade 4, constriction of CCC opening. Uveal inflammation was graded according to the Hogan's criteria. The $\chi^{2}$-test and odds ratio (OR) were used.

We certify that all applicable institutional and governmental regulations concerning the ethical use of human volunteers were followed during this research

\section{Results}

The mean age of the patients was $56.00 \pm 3.00$ years. Circumferential overlap of the IOL optic by the capsulorhexis was achieved and remained same in all the cases at 6 months follow-up. There were no surgical complications that led to patient exclusion. At 1-week follow-up, irrespective of the grade of ACO, there was no significant difference in the development of ACO between the two groups. At the 1-month follow-up, irrespective of the grade of ACO, 54 (90\%) eyes developed ACO in controls and 26 (43.3\%) eyes in cases $(P<0.001)$. At 6 months follow-up, irrespective of the grade of ACO, no significant difference was observed in the development of ACO between the controls and cases $(P=0.500$; Table 1$)$. 
Table 2 Comparison of the grade of anterior capsule opacification (ACO) between the two groups at 1 month after phacoemulsification

\begin{tabular}{lcc}
\hline Grade of ACO & Controls & Cases \\
\hline 0 & $6(10 \%)$ & $34(56.7 \%)$ \\
1 & $44(73.3 \%)$ & $12(20.0 \%)$ \\
2 & $8(13.3 \%)$ & $14(23.3 \%)$ \\
3 & $0(0 \%)$ & 0 \\
4 & $2(3.3 \%)$ & 0 \\
\hline
\end{tabular}

Analysing the grade of ACO, at 1-month follow up, we found that $44(73.3 \%)$ eyes in controls and $12(20 \%)$ eyes in cases showed grade 1 opacification of the anterior capsule. There were significant differences between the two groups $(P<0.001)$. In eight $(13.3 \%)$ eyes in controls and in $14(23.3 \%)$ eyes in cases, the anterior capsule showed grade 2 opacification. There were no significant differences between the two groups. No eyes in either group developed grade 3 ACO. Only two eyes in controls developed grade $4 \mathrm{ACO}$, and none of the eyes in cases developed the same (Table 2).

At 6 months follow-up, while evaluating the grade of $\mathrm{ACO}$, the results for grades 1, 2, and $3 \mathrm{ACO}$ between the two groups were similar with no statistically significant difference (grade 1: $P=0.007$, grade 2: $P=0.009$; and grade 3: $P=0.070$ ). Two eyes in controls had grade 4 ACO (Table 3).

On the first postoperative day, anterior segment inflammation (cells and flare) differed significantly in the two groups, that is, the possibility of detecting cells and flare more than two was significantly higher in cases than in controls (Table 4; cells: OR, 39.27; 95\% CI, 13.49-114.26 and flare: OR, 48.0; 95\% CI, 15.57-147.97).

\section{Discussion}

The postoperative opacification of the capsular bag in the form of ACO and PCO is interpreted as a wound healing response of the residual LECs. ${ }^{18-22}$ Therefore, the removal of residual LECs reduces the chances of development of ACO and PCO. ${ }^{23}$ Several mechanical and chemical means of intraoperative anterior capsule cleaning have also been proposed. Mechanical removal of the LECs is achieved using hydrodissection with rotation and cortical clean-up after phacoemulsification..$^{24,25}$ Mathey $e t a l^{26}$ studied five techniques of polishing the lens capsules. They observed that the cleanest capsule was obtained by using an ultrasound irrigation/aspiration tip. Meucci $e t$ al ${ }^{9}$ also found that ultrasound cleaning was effective in preventing ACO. Few authors have found that silicone scrapers provide rough polishing, and they do not help in complete removal of the epithelial cells. ${ }^{11} \mathrm{Nishi}^{11}$ has
Table 3 Comparison of the grade of anterior capsule opacification (ACO) between the two groups at 6 months after phacoemulsification

\begin{tabular}{lcc}
\hline Grade of ACO & Controls & Cases \\
\hline 0 & 0 & $1(1.7 \%)$ \\
1 & $27(45 \%)$ & $13(21.7 \%)$ \\
2 & $26(43.3 \%)$ & $40(66.7 \%)$ \\
3 & $5(8.3 \%)$ & $6(10 \%)$ \\
4 & $2(3.3 \%)$ & $0(0 \%)$ \\
\hline
\end{tabular}

Table 4 Impact of anterior capsule polishing on anterior segment inflammation on the first postoperative day between the two groups

\begin{tabular}{ccc}
\hline Grade & Controls & Cases \\
\hline $\begin{array}{c}\text { Cells } \\
<2\end{array}$ & & \\
$>2$ & $48(81.4 \%)$ & $6(10 \%)$ \\
Flare & $11(18.6 \%)$ & $54(90 \%)$ \\
$<2$ & & \\
$>2$ & $48(81.4 \%)$ & $5(8.3 \%)$ \\
\hline
\end{tabular}

described ultrasound cleaning of the anterior capsule with a fibrosonic probe. However, a few authors have observed iris pigment dispersion while using the ultrasound method to clean the capsule.

There are several factors, which affect the development of ACO. Both the material and design of IOL impact the development of ACO. ${ }^{27-31}$ The incidence of ACO is lowest with acrylic lenses and highest with plate haptic silicone IOLs. ${ }^{10}$ Nishi and $\mathrm{Nishi}^{19}$ report that fibrous ACO occurs only in that part of the capsule, which faces the anterior surface of posterior capsule IOLs. Further, a few authors postulated that the ACO is the result of fibrous dysplasia of residual LECs on the anterior surface of the IOL. ${ }^{20}$

ACO generally occurs much earlier than PCO and may occur as early as a month after the surgery. ${ }^{8,31,32}$ It has been shown that the anterior capsule opening shrinks rapidly during the first month after cataract surgery and IOL implantation followed by a slower progressive reduction in the subsequent 6 months. ${ }^{8,29,30,33}$ Therefore, we decided to evaluate ACO up to 6 months postoperatively. In this study, ACO was documented and quantified by using a standardized method. It was interesting to note that $\mathrm{ACO}$ was significantly lower at 1 month in cases compared with controls. We hypothesize that this could be due to the use of scraping in cases, which caused a delay in the LECs reaching the anterior surface from the equator. Our results concurred that anterior capsule scraping did not influence ACO at 6 
months postoperatively. ${ }^{2}$ Further, we speculate that ACO developed, despite scraping, due to the proliferation and migration of residual LECs from the germinative zone of the equatorial regions.

The results of this study suggest that a significant difference in anterior segment inflammation was documented in cases on the first postoperative day. We believe that this increase in anterior segment inflammation could be due to the dispersal of the LECs after polishing, which provoke inflammatory mediators. However, further studies with a larger sample size in a controlled environment need to be carried out to assess whether anterior capsule polishing actually increases anterior segment inflammation and causes the residual LECs to migrate anteriorly, thereby negating the effect of polishing.

There are varied opinions about the effect of capsular polishing on the rate of the development and formation of ACO and PCO. The source of LECs for ACO has also been a matter of debate. In general, it is believed that LECs from the equator of the capsular bag play a minor role in the development of anterior cell migration and capsular opacification. The LECs that proliferate into the anterior IOL surface are thought to originate from the anterior capsule close to the capsulorhexis. Further, according to Kruger et $a l^{7}$, polished LECs are not immediately removed by aspiration. These LECs are initially dispersed in the OVD material, and then removed in the second step. There is a possibility that LECs adhere again to the capsule, proliferate, and migrate.

Menapace and collegues ${ }^{3}$ have found that ACO rates are significantly lower in polished eyes compared with unpolished eyes at all follow-up examinations. Sacu et $a l^{2}$ found that although careful anterior capsule polishing reduces $\mathrm{ACO}$ and fibrotic $\mathrm{PCO}$, neither can be completely prevented. This study indicates that anterior capsule polishing did not significantly influence the rates of ACO development. It is well -accepted that one can not remove all the residual LECs, which are attached to capsular bag after surgery using available surgical and chemical means. ${ }^{28}$ In particular, as the population of LECs is divided into pre-equatorial and equatorial cells, it becomes even more difficult to remove them.

Therefore, even though anterior capsular scraping removes a considerable number of LECs, the residual LECs may proliferate and migrate to the anterior capsule leading to ACO. This may be the explanation for our observation that the difference in ACO in the polished and unpolished groups remains significant at 1 month, but become insignificant at 6 months postoperatively.

In this study, we did not evaluate the effect of anterior capsule polishing on the development of PCO. A limitation of this study is that we did not focus on the impact of various factors that influence the impact of anterior capsule polishing on anterior capsule for the development of PCO. To minimize bias in this prospective randomized study, all the surgeries were performed by a single surgeon using a standardized surgical technique with or without anterior capsule polishing depending upon the randomization scheme. Our findings suggest that anterior capsule polishing does not affect ACO at 6 months postoperatively. We conclude that there was no detectable effect and benefit of performing scraping on the anterior capsule to avoid opacification after phacoemulsification.

\section{References}

1 Park TK, Chung SK, Baek NH. Changes in the area of the anterior capsule opening after intraocular lens implantation. J Cataract Refract Surg 2002; 28: 1613-1617.

2 Sacu S, Menapace R, Findl O, Georgopoulos M, Buehl W, Kriechbaum $\mathrm{K}$ et al. Influence of optic edge design and anterior capsule polishing on posterior capsule fibrosis. J Cataract Refract Surg 2004; 30: 658-662.

3 Bolz M, Menapace R, Findl O, Sacu S, Buehl W, Wirtitsch M et al. Effect of anterior capsule polishing on the posterior capsule opacification-inhibiting properties of a sharpedged, 3-piece, silicone intraocular lens: three- and 5-year results of a randomized trial. J Cataract Refract Surg 2006; 32: 1513-1520.

4 Sacu S, Findl O, Menapace R. Assessment of anterior capsule opacification: photographic technique and quantification. J Cataract Refract Surg 2002; 28: 271-275.

5 Marcantonio JM, Vrensen GF. Cell biology of posterior capsular opacification. Eye 1999; 13: 484-488.

6 Azuma N, Hara T, Hara T. Extracellular matrix of opacified anterior capsuleafter endocapsular cataract surgery. Graefes Arch Clin Exp Ophthalmol 1998; 236(7): 531-536.

7 Kruger AJ, Amon M, Schauersberger J, Abela-Formanek C, Schild G, Kolodjaschna J et al. Anterior capsule opacification and lens epithelial outgrowth on the intraocular lens surface after curettage. J Cataract Refract Surg 2001; 27: 1987-1991.

8 Trivedi RH, Werner L, Apple DJ, Pandey SK, Izak AM. Post cataract-intraocular lens (IOL) surgery opacification. Eye 2002; 16: 217-241. review.

9 Meucci G, Esente S, Esente I. Anterior capsule cleaning with an ultrasound irrigating scratcher. J Cataract Refract Surg 1991; 17: 75-79.

10 Werner L, Pandey SK, Apple DJ, Escobar-Gomez M, McLendon L, Macky TA. Anterior capsule opacification: correlation of pathologic findings with clinical sequelae. Ophthalmology 2001; 108: 1675-1681.

11 Nishi O. Removal of lens epithelial cells by ultrasound in endocapsular cataract surgery. Ophthalmic Surg 1987; 18: 577-580.

12 Vasavada AR, Savitha Y, Prajitha T, Ramal UM. Anterior capsule scraping and posterior capsule opacification. J Ophthalmol 1992; 3: 24-28.

13 Miyake K, Ota I, Miyake S, Maekubo K. Correlation between intraocular lens hydrophilicity and anterior capsule opacification and aqueous flare. J Cataract Refract Surg 1996; 22(Suppl 1): 764-769. 
14 Miyake K. Proposal for an ideal surface modification of IOLs. Eur J Implant Refract Surg 1990; 2: 209-212.

15 Arshinoff SA. Dispersive-cohesive viscoelastic soft shell technique. J Cataract Refract Surg 1999; 25(2): 167-173.

16 Vasavada AR, Raj S. Step-down technique. J Cataract Refract Surg 2003; 29(6): 1077-1079.

17 Vasavada A, Singh R. Step-by-step chop in situ and separation of very dense cataracts. J Cataract Refract Surg 1998; 24(2): 156-159.

18 Miyake K, Mackaloo K, Gravagna P, Tayot JL. Collagen IOLs: a suggestion for IOL biocompatibility. Eur J Implant Refract Surg 1991; 3: 99-102.

19 Nishi O, Nishi K. Fibrous opacification of the anterior capsule after cataract syrgery. Jpn J Clin Ophthalmol 1991; 45: 1811-1815.

20 Nishi O. Intercapsular cataract surgery with lens epithelial cell removal. Part II: Effect on prevention of fibrinous reaction. J Cataract Refract Surg 1989; 15: 301-303.

21 Hayashi K, Hayashi H, Nakao F, Hayashi F. Reduction in the area of the anterior capsule opening after polymethylmethacrylate, silicone, and soft acrylic intraocular lens implantation. Am J Ophthalmol 1997; 123: 441-447.

22 Miyake K. Proposal for an ideal surface modification of IOLs. Eur J Implant Refract Surg 1990; 2: 209-212.

23 Nagata T, Minakata A, Watanabe I. Adhesiveness of AcrySof to a collagen film. J Cataract Refract Surg 1998; 24: 367-370.

24 Vasavada AR, Dholakia SR, Raj SM, Singh R. Effect of cortical cleaving hydrodissection on posterior capsule opacification in age- related nuclear cataract. J Cataract Refract Surg 2006; 32: 1196-1200.

25 Vasavada AR, Raj SM, Johar K, Nanavaty MA. Effect of hydrodissection alone and hydrodissection combined with rotation on lens epithelial cells: surgical approach for the prevention of posterior capsule opacification. J Cataract Refract Surg 2006; 32: 145-150.

26 Mathey CF, Kohnen TB, Ensikat HJ, Koch HR. Polishing methods for the lens capsule: histology and scanning electron microscopy. J Cataract Refract Surg 1994; 20(1): 64-69.

27 Werner L, Pandey SK, Escobar-Gomez M, Visessook N, Peng Q, Apple DJ. Anterior capsule opacification: a histopathological study comparing different IOL styles. Ophthalmology 2000; 107: 463-471.

28 Gonvers M, Sickenberg M, van Melle G. Change in capsulorhexis size after implantation of three types of intraocular lenses. J Cataract Refract Surg 1997; 23: 231-238.

29 Hayashi K, Hayashi H, Nakao F, Hayashi F. Reduction in the area of the anterior capsule opening after polymethylmethacrylate, silicone, and soft acrylic intraocular lens implantation. Am J Ophthalmol 1997; 123: 441-447.

30 Kimura W, Yamanishi S, Kimura T, Sawada T, Ohte A. Measuring the anterior capsule opening after cataract surgery to assess capsule shrinkage. J Cataract Refract Surg 1998; 24: 1235-1238.

31 Joo CK, Shin JA, Kim JH. Capsular opening contraction after continuous curvilinear capsulorhexis and intraocular lens implantation. J Cataract Refract Surg 1996; 22: 585-590.

32 Hara T, Azuma N, Chiba K, Ueda Y, Hara T. Anterior capsular opacification after endocapsular cataract surgery. Ophthalmic Surg 1992; 23: 94-98.

33 Hansen SO, Crandall AS, Olson RJ. Progressive constriction of the anterior capsular opening following intact capsulorhexis. J Cataract Refract Surg 1993; 19: 77-82. 